\title{
Nerve Growth Factor Contribution via Transient Receptor Potential Vanilloid 1 to Ectopic Orofacial Pain
}

\author{
Masamichi Shinoda, ${ }^{1,2}$ Masatake Asano, ${ }^{3}$ Daisuke Omagari, ${ }^{3}$ Kuniya Honda, ${ }^{1,4}$ Suzuro Hitomi, ${ }^{1,5}$ Ayano Katagiri, ${ }^{1}$ \\ and Koichi Iwata ${ }^{1,2,6}$ \\ ${ }^{1}$ Department of Physiology, ${ }^{2}$ Division of Functional Morphology, Dental Research Center, and Departments of ${ }^{3}$ Pathology, ${ }^{4}$ Oral and Maxillofacial Surgery, \\ and ${ }^{5}$ Dysphagia Rehabilitation, Nihon University School of Dentistry, Tokyo 101-8310, Japan, and ${ }^{6}$ Division of Applied System Neuroscience Advanced \\ Medical Research Center, Nihon University Graduate School of Medical Science, Tokyo 173-8610, Japan
}

It is well known that oral inflammation causes tenderness in temporomandibular joints or masseter muscles. The exact mechanism of such an orofacial ectopic hyperalgesia remains unclear. Here, we investigated the functional significance of interaction of nerve growth factor (NGF) and transient receptor potential vanilloid 1 (TRPV1) in relation to heat hyperalgesia in the whisker pad skin caused by complete Freund's adjuvant (CFA) injection into the lower lip. CFA injection induced heat hyperalgesia of the ipsilateral whisker pad skin. Moreover, it leads to enhancement of spontaneous activity and heat responses in trigeminal ganglion (TG) neurons that was elicited by heat stimulation of the whisker pad skin. The heat hyperalgesia was dose-dependently reversed by intraperitoneal TRPV1 antagonist administration, also diminished by neutralizing anti-NGF antibody administration into the lower lip and intraganglionic administration of K252a, a tyrosine kinase receptor inhibitor. Nerve fibers in bundle of mandibular nerve and TG neurons that innervates the whisker pad skin and lower lip both expressed labeled NGF, which was administrated into the lower lip. Moreover, the NGF concentrations in ophthalmic-maxillary and mandibular divisions of the TG increased after CFA injection into the lower lip. The number of TRPV1-positive neurons that innervates the whisker pad skin and lower lip was increased after CFA injection into the lower lip, and this increase was annulled by anti-NGF administration. The present findings suggest that inflammation in the lower lip induces release of NGF that regulates TRPV1 expression in TG neurons. This TRPV1 overexpression may underlie ectopic heat hyperalgesia in the whisker pad skin.

\section{Introduction}

It is well known clinically that local inflammation in the oral cavity causes tenderness in masseter muscles or the temporomandibular joint (TMJ) and that patients suffering from TMJ pain sometimes complain of heat hypersensitivity in other orofacial regions (Maixner et al., 1998; Fernández-de-las-Peñas et al., 2010). In a case of neuropathic pain, it is presumed that a nerve injury leads to persistent alterations in the properties of adjacent uninjured, unmyelinated fibers because of changes in expression of ion channels responsible for the membrane excitability (Gold et al., 2003; Shim et al., 2007). In the effort to develop effective treatments for atypical orofacial pain, it is important to establish an appropriate model, and to investigate the exact mechanisms of

\footnotetext{
Received Jan. 28, 2011; revised March 22, 2011; accepted March 24, 2011.

Author contributions: M.S. and K.I. designed research; M.S., M.A., D.O., K.H., S.H., and A.K. performed research; M.A. contributed unpublished reagents/analytic tools; M.S., M.A., K.H., and S.H. analyzed data; M.S., S.H., and K.I. wrote the paper.

This study was supported in part by a research grant from the Dental Research Center, Nihon University School of Dentistry; a Nihon University multidisciplinary research grant; grants from the Ministry of Education, Culture, Sports, Science and Technology to Promote Multidisciplinary Research Project "Translational Research Network on Orofacial Neurological Disorders" at Nihon University School of Dentistry; and the Japan-Canada Joint Health Research Program. We thank Prof. R. Dubner and Dr. A. Binshtok for commenting on this manuscript.

The authors declare no competing financial interests.

Correspondence should be addressed to Dr. Masamichi Shinoda, Department of Physiology, Nihon University School of Dentistry, 1-8-13 Kandasurugadai, Chiyoda-ku, Tokyo 101-8310, Japan. E-mail: shinoda-m@dent.nihon-u.ac.jp.

DOI:10.1523/JNEUROSCI.0481-11.2011

Copyright $\odot 2011$ the authors $\quad 0270-6474 / 11 / 317145-11 \$ 15.00 / 0$
}

ectopic heat hyperalgesia induced by local inflammation in the orofacial region.

The transient receptor potential vanilloid 1 (TRPV1) that belongs to the TRPV subfamily of the large TRP ion channel superfamily is highly expressed in primary sensory neurons. TRPV1 is a critical contributor to normal and pathological pain (Tominaga and Caterina, 2004). This receptor can be activated by noxious heat $\left(>43^{\circ} \mathrm{C}\right)$, extracellular acidification, various lipids, and capsaicin (Caterina et al., 1997; Tominaga and Tominaga, 2005). Several studies demonstrated that TRP channel functions are modulated during inflammation (Ji et al., 2002; Kanai et al., 2007; De Schepper et al., 2008). One of the representations of such a modulation is an inflammatory-mediated heat hyperalgesia (Zhuang et al., 2004; Breese et al., 2005). Among the factors that affect TRPV1 channel function, nerve growth factor (NGF) possesses a central role (Ji et al., 2002). NGF is not required for survival but it has a crucial role in the generation of pain and hyperalgesia in acute and chronic pain states in adults (Hefti et al., 2006). It has been recently demonstrated that intravenous application of NGF causes robust, long-lasting mechanical and thermal hyperalgesia (Lewin et al., 1994; Niewiadomska et al., 2010). Intradermal recombinant human NGF administration of minute doses in humans led to lowering of heat pain threshold (Dyck et al., 1997; Rukwied et al., 2010). One of the possible explanations of such an effect of NGF on pain is that the NGF rapidly potentiates the activity of TRPV1 channels in dorsal root ganglion (DRG) neurons (Shu and Mendell, 1999; Bonnington 
and McNaughton, 2003). DRG neurons cultured in the presence of NGF showed abnormal hyperexcitability (Kitamura et al., 2005). These results suggest that NGF is a potent activator of nociceptors and an endogenous mediator of heat pain sensation.

The aim of the present study is to test the hypothesis that (1) local inflammation in the mandibular division (V3) plays a role in heat nociception in the ophthalmic-maxillary division (V1$\mathrm{V} 2)$, (2) NGF produced by local inflammation in the V3 is retrogradely transported to the trigeminal ganglion (TG), and (3) upregulation and/or sensitization of TRPV1 in TG neurons in V1-V2 after lower lip inflammation facilitate the transmission of nociceptive information via functional interactions among TG neurons.

\section{Materials and Methods}

Animals. Male C57BL/6 mice (20-30 g) were used in this study (Japan SLC). Mice were exposed to a $12 \mathrm{~h}$ light/dark cycle and kept in a temperature-controlled room $\left(23^{\circ} \mathrm{C}\right)$ with food and water ad libitum. This study was conducted in accordance with the ethical guidelines of the International Association for the Study of Pain (Zimmermann, 1983) and was approved by the local animal ethics committee in accordance with the Guidelines for Animal Experiments in Nihon University School of Dentistry.

Induction of inflammation in lower lip. Under anesthesia with intraperitoneal injection of sodium pentobarbital (50 mg/kg; Schering Plough), mice were injected with a $3 \mu \mathrm{l}$ of solution of complete Freund's adjuvant (CFA) (Sigma-Aldrich) or physiological saline subcutaneously into the left lower lip.

Assessment of heat sensitivity of whisker pad skin. To assess nocifensive responses to heat stimuli, mice were briefly sedated with $2 \%$ isoflurane (Mylan) and gently placed in a restraint device, manufactured as described previously (Kamp et al., 2003), inside a sound-attenuating, dark chamber, and allowed to recover from isoflurane sedation (30 $\mathrm{min}$ ) before behavioral assay. Radiant heat was applied to the left whisker pad skin. The head withdrawal latency to radiant heat was manually recorded with a chronometer before CFA injection into the left lower lip to assess basal levels. The same procedure was performed on days 2, 4, 6, 8, 10, 12, and 14 after CFA injection into the left lower lip. A cutoff of $10 \mathrm{~s}$ was established to prevent tissue damage.

$T G$ neuronal recording. Mice were initially anesthetized with urethane $(1.2 \mathrm{mg} / \mathrm{kg}$, i.p.), and spontaneous activity and evoked responses of TG neurons by heat stimulation of the whisker pad skin were recorded on day 4 after CFA or saline injection into the lower lip. Mice were mounted in a stereotaxic frame, the cortical surface was exposed by a craniotomy, and dura was removed from the exposed brain surface to insert recording electrodes into the TG through the cortex (anterior, 2.5-3.0 mm; left, $0.5-1.2 \mathrm{~mm}$; depth, 5.5-6.2 $\mathrm{mm}$, from the bregma). Mice were anesthetized with continuous inhalation of $2-3 \%$ isoflurane mixed with oxygen, and immobilized with pancuronium bromide $(3.3 \mathrm{mg} / \mathrm{kg} / \mathrm{h}$, i.p.) during recording session. End-tidal $\mathrm{CO}_{2}$ was maintained from 3.5 to $4.5 \%$ and the rectal temperature was maintained at $37^{\circ} \mathrm{C}$ by a feedback-controlled heating blanket. The electrocardiogram was monitored and the heart rate was maintained at $400-500 / \mathrm{min}$. When the heart rate was increased during heat stimulation, the concentration of isoflurane was increased appropriately. After identification of heat-sensitive TG neurons innervating whisker pad skin (whisker pad TG neurons) using tungsten microelectrodes (impedance, $10 \mathrm{M} \Omega$ ), the single neuronal activity was amplified and stored in the computer hard disk. Spikes were sorted and spike frequencies were analyzed using the Spike II software (CED 1401; Cambridge Electronic Design).

Spontaneous activity and evoked responses by heat stimulation of the whisker pad skin $\left(55^{\circ} \mathrm{C}, 10 \mathrm{~s}\right)$ using a contact thermode (Intercross) were analyzed on day 4 after injection of CFA or saline into the lower lip.

Effect of TRPV1 antagonist on heat hyperalgesia. To assess the involvement of TRPV1 in heat hyperalgesia of the whisker pad skin induced by CFA injection into the lower lip, CFA-injected animals were administered with the TRPV1 antagonist $N$-(3-methoxyphenyl)-4-chlorocinnamide
(SB366791) (Sigma-Aldrich). SB366791 was dissolved in 50\% dimethylsulfoxide in saline. On day 4 after injection of CFA into the lower lip, SB366791 (0.1, 1.0, and $10 \mathrm{mg} / \mathrm{kg}$, i.p.) was administrated in a volume of $0.1 \mathrm{ml}$. These doses of SB366791 were determined from previous reports (Varga et al., 2005). Head withdrawal latency to radiant heating of the whisker pad skin was determined before (pre) and $0,30,60$, and $90 \mathrm{~min}$ after intraperitoneal administration of SB366791. Control animals received the same volume of vehicle.

Peripheral administration of neutralizing anti-NGF antibody. To assess the involvement of NGF in the heat hyperalgesia of whisker pad skin induced by CFA injection into the lower lip, $3 \mu$ l of anti-NGF antibody ( 1 $\mu \mathrm{g} / \mathrm{kg} / \mathrm{d}$, s.c.; Santa Cruz) was administrated into the lower lip for 4 successive days (day 0 through day 3 ) in CFA-injected mice. Anti-NGF antibody was dissolved in saline, with the dose of anti-NGF antibody determined from a previous report (Delafoy et al., 2003). Head withdrawal latency to radiant heating of the whisker pad skin was determined on day 4 after injection of CFA into the lower lip. Control animals received the same volume of vehicle.

Peripheral administration of NGF. To assess the involvement of NGF into the lower lip in heat hyperalgesia of the whisker pad skin, $3 \mu \mathrm{l}$ of NGF $2.5 \mathrm{~S}$ (5 $\mu \mathrm{g} / \mathrm{kg}$, s.c.; Sigma-Aldrich) dissolved in saline was administrated into the lower lip for 4 successive days (day 0 through day 3 ) in naive mice. The dose of NGF $2.5 \mathrm{~S}$ was determined from a previous report (Delafoy et al., 2003). Head withdrawal latency to radiant heating of the whisker pad skin was determined on day 4 according to the methods described above. Control animals received the same volume of vehicle.

TRPV1 expression in whisker pad TG neurons or TG neurons innervating lower lip (lower lip TG neurons). whisker pad or lower lip TG neurons were identified by means of the retrograde labeling with $3 \%$ hydroxystilbamidine [FluoroGold (FG)] (Fluorochrome) dissolved in saline or $100 \mathrm{mg} / \mathrm{ml}$ (in $100 \%$ ethanol) of 1,1'-dioctadecyl-3,3,3',3-tetramethylindocarbocyanine methanesulfonate (DiI) (Invitrogen). In advance, FG injection $(3 \mu \mathrm{l})$ into the ipsilateral whisker pad skin and DiI injection $(3 \mu \mathrm{l})$ into the ipsilateral lower lip were performed with a 30 gauge needle before injection of CFA or saline into the lower lip.

On day 4 after CFA or saline injection into the lower lip, CFA-injected animals receiving anti-NGF antibody or saline daily into the lower lip were anesthetized with sodium pentobarbital (50 mg/kg, i.p.) and transcardially perfused with saline followed by a fixative containing $4 \%$ paraformaldehyde in $0.1 \mathrm{~m}$ phosphate buffer, $\mathrm{pH}$ 7.4. Each group consisted of five animals. Ipsilateral TGs were dissected out after perfusion and immersed in the same fixative for $4 \mathrm{~h}$ at $4^{\circ} \mathrm{C}$. Postfixed TGs were kept in 0.01 M PBS containing 20\% sucrose for $12 \mathrm{~h}$ for cryoprotection. The specimens were then embedded in TissueTek (Sakura Finetek) and stored until cryosectioning at $-20^{\circ} \mathrm{C}$. TGs were cut in the horizontal plane along the long axis of the ganglion on a cryostat at a thickness of $10 \mu \mathrm{m}$. For analysis, every 10th section-four sections per TG-was chosen for each mouse. Sections were thaw-mounted onto MAS-coated Superfrost Plus microscope slides (Matsunami) and dried at dark room temperature overnight.

TG sections were incubated with rabbit anti-TRPV1 polyclonal antiserum (Alomone) after dilution at a concentration of 1:500 in 0.01 м PBS containing $4 \%$ normal goat serum and $0.3 \%$ Triton X-100 (SigmaAldrich). Sections were reacted with the reagent for overnight at $4^{\circ} \mathrm{C}$. After rinsing with $0.01 \mathrm{M}$ PBS, sections were reacted with Alexa Fluor 488-conjugated goat anti-rabbit IgG (1:200 in $0.01 \mathrm{M}$ PBS; Invitrogen) for $2 \mathrm{~h}$ at room temperature. After rinsing with $0.01 \mathrm{M}$ PBS, sections were coverslipped in mounting medium (Thermo Fisher Scientific) and examined under a fluorescence microscope. Using appropriate filters, double-labeled (FG or DiI, with Alexa Fluor 488) neurons were identified and analyzed using a BZ-9000 system (Keyence). Neurons twofold or more intense than average background were considered positive for TRPV1 immunoreactivity. No specific labeling was observed in the absence of primary antibody. The ratio of TRPV1-positive neurons in each animal was calculated by the following formula: $100 \times$ total number of TRPV1-positive and FG- or DiI-labeled neurons in four sections of TG/ total number of FG- or DiI-labeled neurons in four sections of TG. Mean percentages of TRPV1-positive neurons in FG- or DiI-labeled neurons were calculated from the ratio of five animals. 


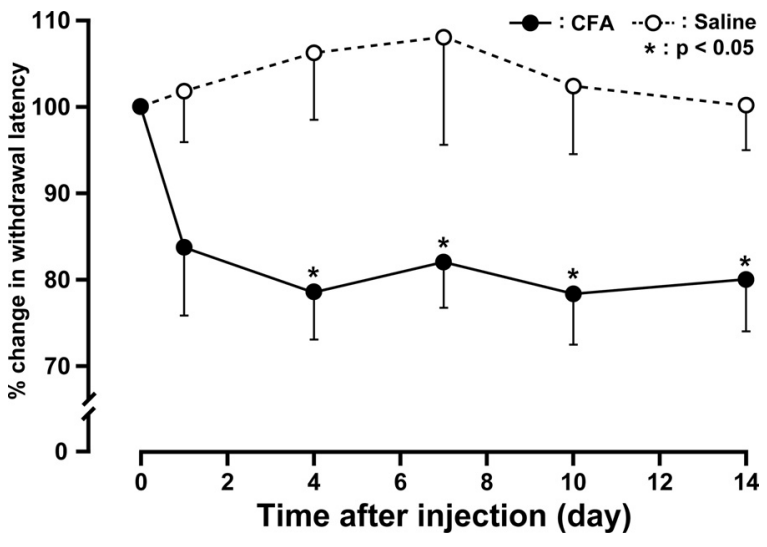

Figure 1. Changes in heat sensitivity measured in whisker pad skin for $14 \mathrm{~d}$. CFA or saline was injected into the ipsilateral lower lip. Data are expressed as percentage (mean \pm SEM) for withdrawal latency for each animal, normalized to withdrawal latency $(100 \%)$ on preinjection. ${ }^{*} p<0.05 \mathrm{com}-$ pared with withdrawal latency of saline-injected animals ( $n=6$ in each group; two-way ANOVA with repeated measures, followed by Bonferroni's multiple-comparison tests).

NGF receptors and extracellular signal-regulated kinase phosphorylation expression in whisker pad TG neurons. whisker pad TG neurons were identified by means of retrograde labeling with $3 \% \mathrm{FG}$ injection ( $3 \mu$ l, s.c.) performed with a 30 gauge needle inserted into the ipsilateral whisker pad skin before CFA injection. On day 4 after CFA injection into the lower lip, CFA-injected animals were anesthetized with sodium pentobarbital ( $50 \mathrm{mg}$ / $\mathrm{kg}$, i.p.) and transcardially perfused with saline followed by a fixative containing $4 \%$ paraformaldehyde in $0.1 \mathrm{M}$ phosphate buffer, $\mathrm{pH}$ 7.4. To identify TrkA, p75 receptors, and extracellular signal-regulated kinase (ERK) phosphorylation (pERK) expression immunohistochemically in TG, anti-TrkA rabbit polyclonal antibody (1:100; Millipore), anti-p75 goat antibody (1:200; Neuromics), and anti-phospho-p44/42 mitogen-activated protein kinase (MAPK; Thr $^{202} / \mathrm{Tyr}^{204}$ ) rabbit antibody (1:200; Cell Signaling Technology) were used as a primary antibody, and Alexa Fluor 488-conjugated goat antirabbit IgG or donkey anti-goat IgG (Invitrogen) was used as a secondary antibody. Immunohistochemical staining and calculation of positive neurons were performed as described in the previous section.

Western blotting analysis. On day 4 after injection of CFA or saline into the lower lip, animals were anesthetized with sodium pentobarbital (50 $\mathrm{mg} / \mathrm{kg}$, i.p.) and transcardially perfused with saline. TG was taken out rapidly and divided into ophthalmic-maxillary (V1-V2) and mandibular divisions (V3). The tissue was homogenized in $200 \mu \mathrm{l}$ of ice-cold lysis buffer (137 mm NaCl, 20 mm Tris-HCl, pH 8.0, 1\% NP40, 10\% glycerol, $1 \mathrm{~mm}$ phenylmethylsulfonyl fluoride, $10 \mu \mathrm{g} / \mathrm{ml}$ aprotinin, $1 \mathrm{~g} / \mathrm{ml}$ leupeptin, and $0.5 \mathrm{~mm}$ sodium vanadate) using a tube pestle (Thermo Fisher Scientific). Samples were then centrifuged at $15,000 \mathrm{rpm}$ for $10 \mathrm{~min}$ at $4^{\circ} \mathrm{C}$. Supernatants were collected to new tubes and protein concentrations of the samples were determined with a protein assay kit (Bio-Rad) and subjected to Western blotting and ELISA. For Western blotting, $100-200 \mu \mathrm{g}$ of total protein was subjected to $10 \%$ SDS-PAGE. The separated protein was transferred to an Immobilon membrane (Millipore) electrophoretically, and Western blotting was performed as described previously (Asano et al., 2004). The rabbit anti-TRPV1 antibody (1:200 dilution with $1 \%$ bovine serum albumin (BSA)-PBST in $0.1 \%$ Tween 20-PBS; Alomone) was used as the primary antibody. Horseradish peroxidase-conjugated goat anti-rabbit $\operatorname{IgG}(\mathrm{H}+\mathrm{L})(1: 5000$ dilution with $1 \%$ BSA-PBST; Jackson ImmunoResearch) was used as the secondary antibody. The bands were detected using an ECL kit (GE Healthcare) and were captured by a scanner. The intensities of the bands were quantified by NIH Image analysis system. The intensities of TRPV1 bands were normalized with that of GAPDH bands. The intensity ratio was set as $100 \%$ when saline was injected into the lower lip.

Peripheral administration of labeled recombinant NGF. The Alexa Fluor 488 labeling of $\beta$-NGF (R\&D Systems) was performed with Alexa Fluor 488 microscale protein labeling kit (Invitrogen). Briefly, $50 \mu \mathrm{g}$ of $\beta$-NGF was mixed with $5 \mu \mathrm{l}$ of $1 \mathrm{M}$ sodium bicarbonate and pipetted thoroughly.



Heat response
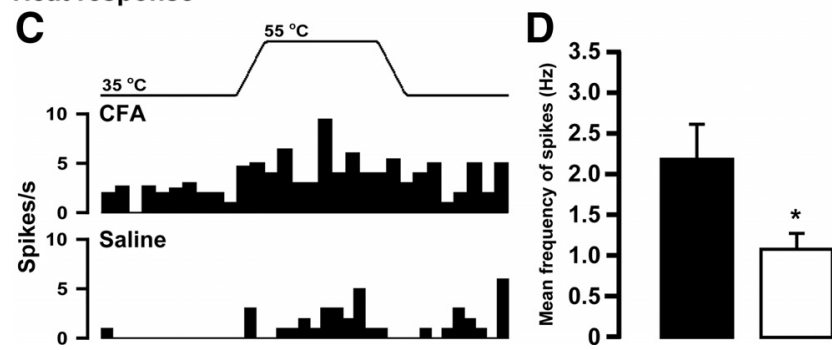

Figure 2. Effect of injection of CFA or saline into the lower lip on spontaneous activity and heat responses of whisker pad TG neurons. $\boldsymbol{A}, \boldsymbol{C}$, Typical peristimulus time histograms of spontaneous activities $(\boldsymbol{A})$ and heat responses $(\boldsymbol{C})$ of TG neurons. $\boldsymbol{B}, \boldsymbol{D}$, Mean firing frequency of spontaneous activity $(\boldsymbol{B})$ and heat response $(\boldsymbol{D}) .{ }^{*} p<0.05,{ }^{* *} p<0.01$ versus saline-injected ( $n=5$ in each group; Student's $t$ test). Error bars indicate SEM.

The sample was further mixed with $2.6 \mu$ l of Alexa Fluor 488 solution and incubated for $15 \mathrm{~min}$ at room temperature. The reaction mixture was applied to the spin column and unreacted dye was eliminated. The flowthrough was collected and the protein concentration was measured. The labeled protein was aliquoted and stored at $-80^{\circ} \mathrm{C}$ until use. In advance, FG injection $(3 \mu \mathrm{l})$ into the ipsilateral whisker pad skin and DiI injection $(3 \mu \mathrm{l})$ into the ipsilateral lower lip were performed with a 30 gauge needle before injection of CFA or saline into the lower lip. CFA or saline with 3 $\mu \mathrm{l}$ of Alexa Fluor 488 -labeled $\beta$-NGF $(1 \mu \mathrm{g} / \mu \mathrm{l}$, s.c. $)$ was administrated into the lower lip in mice. On day 1 after CFA or saline injection with Alexa Fluor 488-labeled $\beta$-NGF into the lower lip, the animals were perfused with $4 \%$ paraformaldehyde and TGs were cut in the horizontal plane along the long axis of the ganglion on a cryostat as described above. After rinsing with $0.01 \mathrm{M}$ PBS, sections were coverslipped in mounting medium (Thermo Fisher Scientific) and examined under a fluorescence microscope. Using appropriate filters, FG and Alexa Fluor 488 doublelabeled neurons and Alexa Fluor 488-labeled nerve fibers were identified. The mean percentages of NGF-positive neurons in FG- or DiI-labeled neurons were calculated as described in the previous section. The Alexa Fluor 488 labeling of BSA was conducted, administered with CFA or saline into the lower lip, and examined under equal conditions as described above.

ELISA measurements of NGF. On days $0.5,1,4$, and 10 after injection of CFA or saline into the lower lip, animals were anesthetized with sodium pentobarbital $(50 \mathrm{mg} / \mathrm{kg}$, i.p.) and transcardially perfused with saline. Supernatants were taken from V1-V2 and V3 in TG, the lower lip, whisker pad skin, and supraorbital regions by the method described above (see Western blotting analysis).

Sympathetic postganglionic neurons are notorious for their ability to take up and transport NGF. These axons of the superior cervical ganglion (SCG) run in large numbers through the TG on the way to the face and could be the source of NGF protein changes in the TG. Animals were anesthetized with sodium pentobarbital (50 mg/kg, i.p.), the SCG was exposed surgically (cervical incision, $\sim 1 \mathrm{~cm}$ in length), and removal of the ipsilateral SCG or sham operation was performed. The incision was closed with 5-0 silk sutures, and animals were subsequently returned to their home cages until use. Animals were anesthetized and perfused on day 1 after injection of CFA into the lower lip; supernatants were taken from V1-V2 and V3 in TG by the method described above (see Western blotting analysis). 

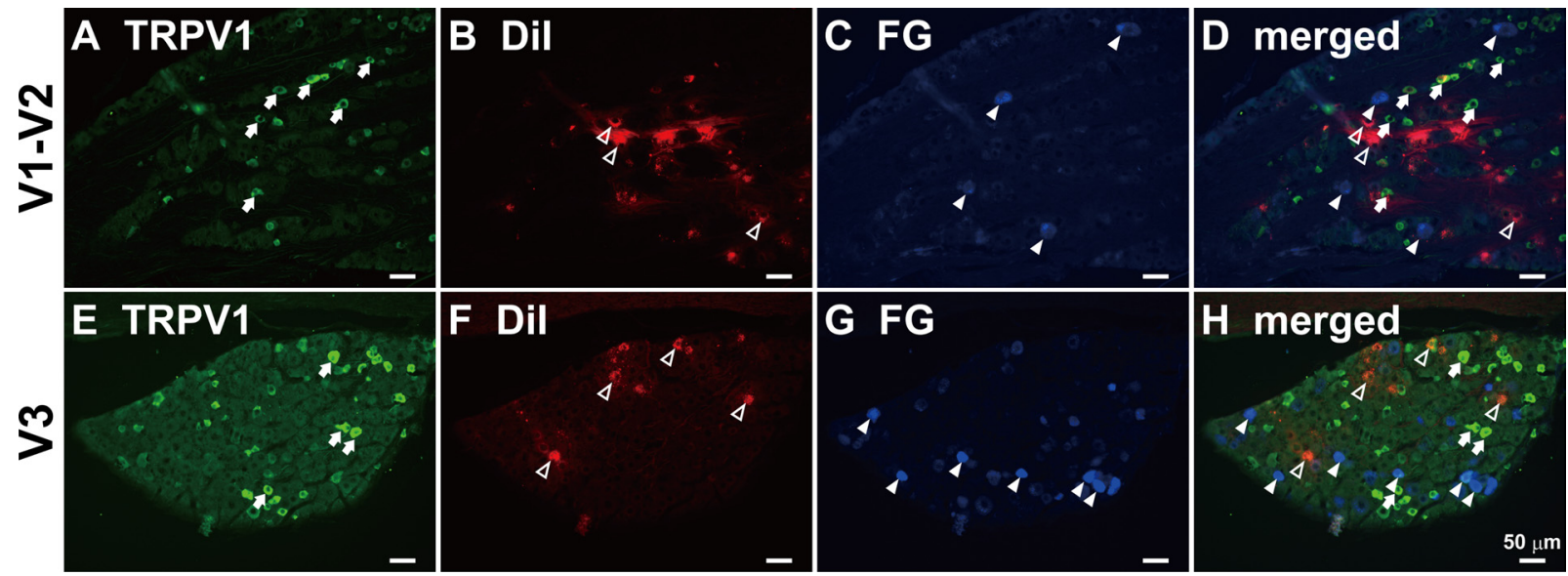

Figure 3. On day 4 after CFA injection, TRPV1-positive whisker pad or lower lip TG neurons in V1-V2 (A-D) and V3 (E-H) defined by FG or Dil, respectively. $\boldsymbol{A}, \boldsymbol{E}$, TRPV1-positive TG neurons. $\boldsymbol{B}$, $\boldsymbol{F}$, Dil-labeled TG neurons. $\boldsymbol{C}, \mathbf{G}$, FG-labeled TG neurons. $\boldsymbol{D}$, H, Dil- and FG-labeled $\beta$-NGF-positive TG neurons. Arrows, TRPV1-positive TG neurons. Open arrowheads, Dil-labeled TG neurons. Arrowheads, FG-labeled TG neurons. Scale bar, $50 \mu \mathrm{m}$.

A



B

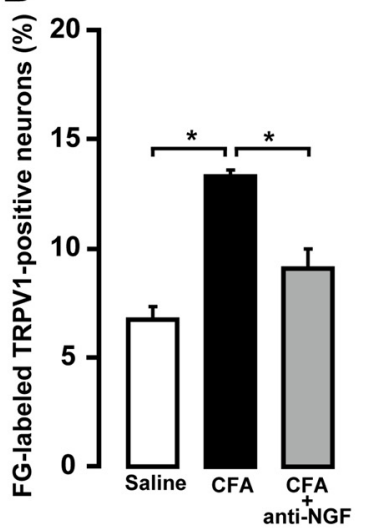

FG

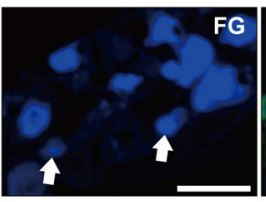

C

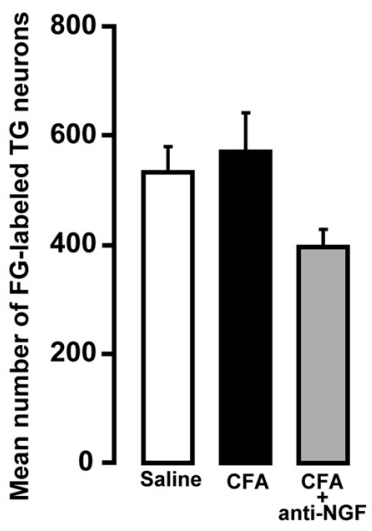

D



E



$\mathbf{F}$

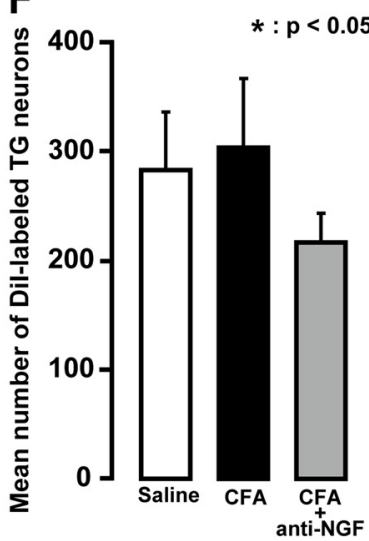

Figure 4. $\quad$ A, TRPV1 immunoreactivity of whisker pad TG neurons defined by FG. B, Frequency of FG-labeled TRPV1-positive TG neurons. C, Mean number of FG-labeled TG neurons. $\boldsymbol{D}$, TRPV1 immunoreactivity of lower lip TG neurons defined by Dil. $\boldsymbol{E}$, Frequency of Dil-labeled TRPV1-positive TG neurons. $\boldsymbol{F}$, Mean number of Dil-labeled TG neurons. The arrow indicates a double-labeled neuron. Scale bar, $50 \mu \mathrm{m} .{ }^{*} p<0.05$ ( $n=5$ in each group; one-way ANOVA followed by Bartlett's multiple comparisons). Error bars indicate SEM.

The concentration of NGF in $100 \mu \mathrm{g}$ of total protein was quantified using the E-max immunoassay system (Promega) according to the manufacturer's instructions. Absorbance values of standards and samples were corrected by subtraction of the background value to correct for absorbance attributable to nonspecific binding. Absorbance was measured using a Microplate reader model 3550 (Bio-Rad).

Intraganglionic administration of K252a. Mice were anesthetized with sodium pentobarbital (50 mg/kg, i.p.) and placed in a stereotaxic apparatus, and then a guide cannula was implanted into the left TG (anterior, $2.5 \mathrm{~mm}$; left, $1.0 \mathrm{~mm}$; depth, $5.5 \mathrm{~mm}$, from the bregma). The guide cannula was kept detaining with stainless-steel screws and dental resin. After completion of surgery, mice were allowed to recover for 9-10 d before experiments were performed.

To assess the involvement of intraganglionic NGF induced by CFA injection into the lower lip in the heat hyperalgesia of whisker pad skin, $0.5 \mu \mathrm{l}$ of (9S- $(9 \alpha, 10 \beta, 12 \alpha)$ )-2,3,9,10,11,12-hexahydro-10-hydroxy-10-(methoxycarbonyl)-9-methyl-9,12-epoxy-1 $H$-diindolo[1,2,3-fg:3', $2^{\prime}, 1^{\prime}$-kl] pyrrolo[3,4-i][1,6]benzodiazocin-1-one (K252a), a nonselective tyrosine kinase receptor inhibitor ( $1 \mu \mathrm{g} / \mathrm{d}$; Santa Cruz), was administered into TG via a 31 gauge, 6.0-mm-long needle for 4 successive days (day 0 through day 3 ) in CFA-injected mice. K252a was dissolved in $0.01 \mathrm{~m}$ PBS in 5\% DMSO. Head withdrawal latency to radiant heating of the whisker pad skin was determined on day 4 after injection of CFA into the lower lip. Control animals received the same volume of vehicle.

Total RNA extraction and reverse transcription-PCR. To detect NGF mRNA expression in the lower lip and TG before and at $12 \mathrm{~h}$ after injection of CFA or saline into the lower lip, animals were anesthetized with sodium pentobarbital $(50 \mathrm{mg} / \mathrm{kg}$, i.p.) and transcardially perfused with saline. The lower lip and TG divided into V1-V2 and V3 were dissected and frozen rapidly. Total RNA in lower lip, V1-V2, and V3 was purified using an RNeasy mini kit (Qiagen). One microgram of total RNA was subjected to first-strand cDNA synthesis as described previously (Omagari et al., 2008). The cDNA was amplified by sequence-specific primers for NGF and $\beta$-actin. The primers used in this study were as follows: NGF, $915 \mathrm{bp}$, forward primer, $5^{\prime}$-GCATGGTGGAGTTTTGGC3'; reverse primer, 5'-AGGAGAGTGTGGAGGGGG-3'; $\beta$-actin, 225 bp, 
A

\section{Ophthalmic-maxillary division}
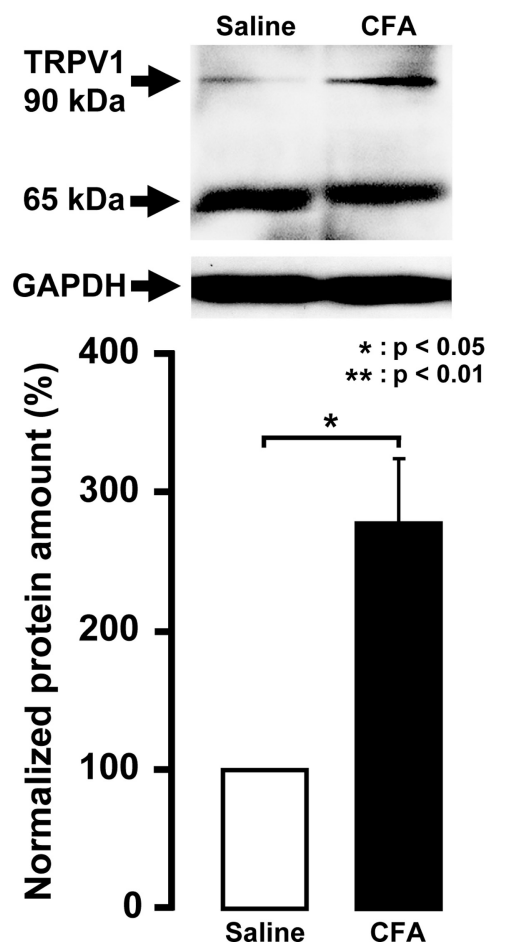

\section{B Mandibular division}

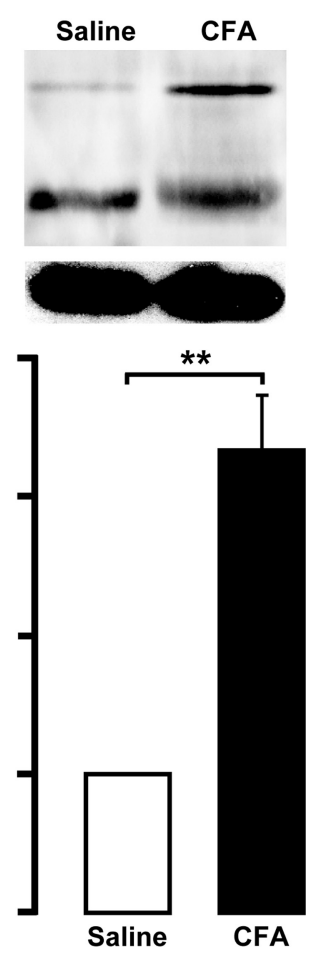

Figure 5. Normalized amount of TRPV1 protein on day 4 after CFA injection into the lower lip in TG in V1-V2 (A) and V3 (B). GAPDH was used as a loading control for TG. * $p<0.05$ versus saline-injected TG ( $n=6$ in each group; Student's $t$ test). Error bars indicate SEM.

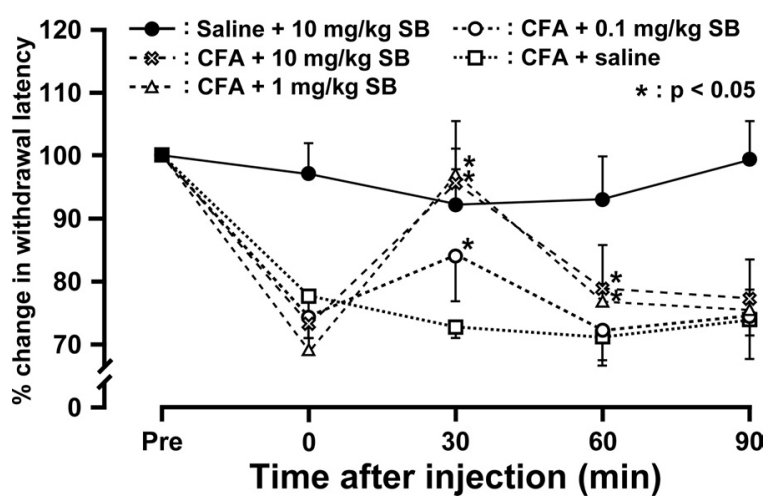

Figure 6. Time course of changes in heat sensitivity in whisker pad skin of CFA-injected or saline-injected mice after administration of the TRPV1 antagonist SB366791. Head withdrawal latency increased after administration of SB366791 in CFA-injected mice, but not in salineinjected. Head withdrawal latency was measured from 0 to 90 min after SB366791 administration. Data are expressed as percentage (mean \pm SEM) for head withdrawal latency for each animal, normalized to head withdrawal latency $(100 \%)$ on preadministration. ${ }^{*} p<0.05 \mathrm{com}$ pared with head withdrawal latency before administration of SB366791 ( $n=5$ in each group; two-way ANOVA with repeated measures followed by Bonferroni's multiple-comparison tests).

forward primer, 5'-TTCCAGCCTTCCTTCCTGG-3'; reverse primer, $5^{\prime}$-TTGCGCTCAGGAGGAGCAA-3'. The PCR products were separated by agarose gel electrophoresis. The intensity of both NGF and $\beta$-actin bands was measured by NIH Image system and the relative ratio was calculated. NGF mRNA expression level in the lower lip induced by CFA injection was set as 1 .

Statistical analysis. Data were expressed as means \pm SEM. Statistical analyses were performed by Student's $t$ test, one-way ANOVA followed by Dunnett's multiple-comparison tests, or two-way repeated-measures
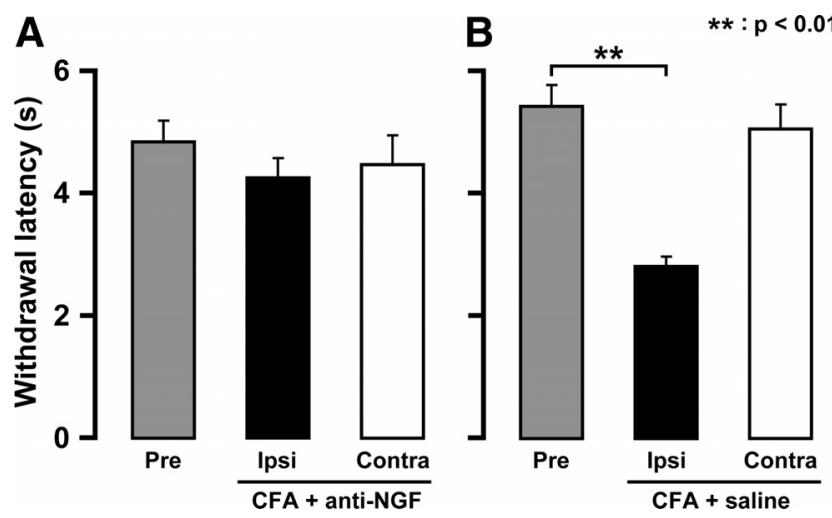

Figure 7. Effects of neutralizing anti-NGF antibody on heat sensitivity of CFA-injected animals. Values of histograms are represented as mean $\pm \mathrm{SEM}$. Effect of lower lip neutralizing anti-NGF antibody $(\boldsymbol{A})$ or saline $(\boldsymbol{B})$ administrations on heat sensitivities of whisker pad skin on day 4 after CFA injection. Gray, whisker pad skin preinjection. Black, whisker pad skin ipsilateral to CFA-injected lower lip. White, whisker pad skin contralateral to CFA-injected lower lip. ${ }^{* *} p<$ 0.01 ( $n=5$ in each group; one-way ANOVA followed by Bartlett's multiple-comparison test).
A

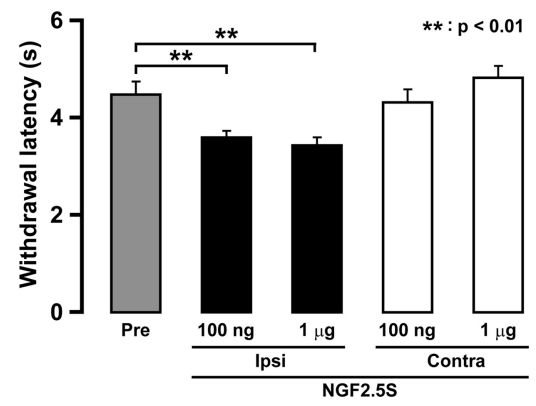

B

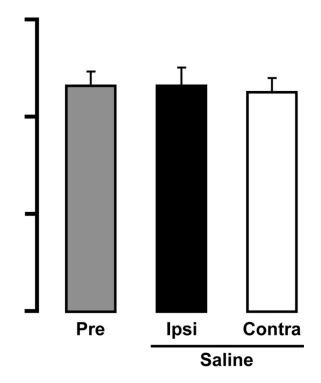

Figure 8. Effects of administration of NGF 2.55 into the lower lip on heat sensitivity of whisker pad skin. Values of histograms are represented as mean \pm SEM. Effect of lower lip NGF $2.5 \mathrm{~S}(\boldsymbol{A})$ or saline $(\boldsymbol{B})$ administrations on heat sensitivities of whisker pad skin on day 4. Gray, whisker pad skin of preinjection. Black, Ipsilateral whisker pad skin. White, Contralateral whisker pad skin. ${ }^{* *} p<0.01$ ( $n=5$ in each group; one-way ANOVA followed by Bartlett's multiplecomparison test).

ANOVA followed by Bonferroni's multiple-comparison tests where appropriate. A value of $p<0.05$ was considered significant.

\section{Results}

Heat hyperalgesia in whisker pad skin after CFA injection into the lower lip

We first studied the changes in the heat withdrawal latency after lower lip injection of CFA. Mice receiving a unilateral lower lip injection of CFA developed lip inflammation with swelling on day 1 . The heat withdrawal latency of the whisker pad skin significantly decreased after CFA injection into the ipsilateral lower lip (80.9 $\pm 6.6 \%$ in change; $3.4 \pm 0.2 \mathrm{~s}$ ) compared with salineinjected controls (106.2 $\pm 7.6 \%$ in change; $4.2 \pm 0.2 \mathrm{~s})$ on day 4 after injection. Significant heat hyperalgesia was observed in the ipsilateral whisker pad skin on day 4 through day $14(p<0.05)$ (Fig. 1). There were no significant changes in heat withdrawal latency of the saline-injected whisker pad skin during the experimental period. No significant changes in heat withdrawal latency of the contralateral whisker pad skin were observed during the experimental period compared with the basal value before injection (data not shown). Animals ate and gained weight normally during the experimental period. 
Changes in excitability of whisker pad TG neurons after CFA injection into the lower lip

whisker pad TG neurons in CFA-injected $(n=5)$ and saline-injected mice $(n=5)$ were functionally identified on day 4 after CFA or vehicle injection. Spontaneous activity in whisker pad TG neurons significantly increased in CFA-injected mice compared with saline-injected $(p<0.01)$ (Fig. 2A,B). Moreover, evoked responses by heat stimulation of the whisker pad skin were significantly larger in CFAinjected mice than that of saline-injected $(p<0.05)$ (Fig. 2C,D).

\section{TRPV1 expression in whisker pad TG neurons}

We then studied whether changes in expression of TRPV 1 channels may underlie the CFA-mediated hyperalgesia and the changes of excitability of TG neurons. We examined the presence of TRPV1 immunoreactivity in whisker pad and lower lip TG neurons using immunofluorescence techniques combined with retrogradetracing fluorescent neuronal tracer FG or DiI (Fig. 3). Retrogradely labeled neurons were observed in TG after injections of FG into the whisker pad skin or DiI into the lower lip. FG-labeled neurons containing TRPV1 were present in TG (Fig. 4A). Mean percentage of FG-labeled TRPV1-positive neurons was significantly increased on day 4 after CFA injection $(13.3 \pm 0.4 \%)$ compared with saline $(6.7 \pm 0.6 \%$; $p<0.05)$. Daily anti-NGF antibody application after CFA injection prevented the increase in number of TRPV1-expressing neurons $(9.1 \pm 0.9 \%)$ (Fig. $4 B$ ). There were no differences in the mean number of total FG- and DiI-labeled neurons in the TG ipsilateral to CFA, CFA plus anti-NGF antibody, or saline injection (Fig. 4C,F).

DiI-labeled neurons containing TRPV1 were present in TG (Fig. 4D). Mean percentage of DiI-labeled TRPV1-positive neurons was significantly increased on day 4 after CFA injection $(44.7 \pm 5.1 \%)$ compared with saline $(27.8 \pm 3.9 \% ; p<0.05)$, but returned to the value of saline-injected group after CFA injection with daily antiNGF antibody application $(24.1 \pm 1.7 \%)$ (Fig. $4 E$ ).

On day 4 after CFA injection, the protein expressions of TRPV1 in V1-V2 or V3 of TG were assessed by Western blotting of protein extracts. TRPV1 protein expression in both V1-V2 and V3 of TG ipsilateral to CFA injection was significantly greater than that of the saline-injected group (278.7 $\pm 46.7 \%$ in V1-V2 and $334.0 \pm 39.8 \%$ in V3, respectively) (Fig. $5 A, B)(p<0.05)$.

\section{TRPV1 mediates heat hyperalgesia in whisker pad skin}

Effects of the TRPV1 antagonist SB366791 on heat hyperalgesia of the whisker pad skin were tested on day 4 after CFA injection. The SB366791 administration produced a marked dose-dependent reversal of CFA induced-heat hyperalgesia in the whisker pad skin (Fig. 6). Recovery in head withdrawal latency peaked at $30 \mathrm{~min}$ after SB366791 administration. SB366791 had no effect on heat withdrawal latencies of the whisker pad skin at the control conditions. Motor deficits or sedation were not observed during the experimental period (data not shown).
Effect of anti-NGF antibody administration into the lower lip on heat hyperalgesia in whisker pad skin

Four days after CFA injection into the lower lip, daily anti-NGF antibody administration (day 0 through day 3 ) into the lower lip had no effect on head withdrawal latency to heat stimulation of the whisker pad skin (Fig. 7 A,B). Moreover, daily anti-NGF antibody alone had no effect on head withdrawal latency (data not shown).

Effect of NGF 2.5S administration into the lower lip on heat hyperalgesia in whisker pad skin

Four days after daily NGF 2.5S administration into the lower lip, head withdrawal latency to heat stimulation of the whisker pad skin was significantly shortened by daily NGF $2.5 \mathrm{~S}$ administration (day 0 through day 3 ) into the lower lip compared with that before administration $(p<0.01)$ (Fig. $8 A$ ). There was no significant difference in head withdrawal latency between groups receiving $100 \mathrm{ng}$ and $1 \mu \mathrm{g}$ of NGF 2.5S. No change in head withdrawal latency was observed in the saline-injected group (Fig. 8B).

\section{TrkA, p75, and pERK expression in TG}

The presence of TrkA-, p75-, or pERK-positive whisker pad TG neurons was examined by immunohistochemical staining combined with retrograde tracing of FG. whisker pad TG neurons on day 4 after CFA injection expressed TrkA, p75, or pERK (Fig. 9). In FG-labeled neurons in TG ipsilateral to CFA injection, mean percentage of TrkA-positive neurons was not altered, whereas that of p75-positive neurons was significantly decreased (CFAinjected, $17.9 \pm 1.2 \%$; saline-injected, $26.6 \pm 2.5 \%$; $p<0.05$ ). Mean percentage of FG-labeled pERK-positive neurons slightly increased in TG ipsilateral to CFA injection (CFA-injected, $32.9 \pm 5.7 \%$; saline-injected, $18.5 \pm 2.7 \% ; p=0.052$ ). 

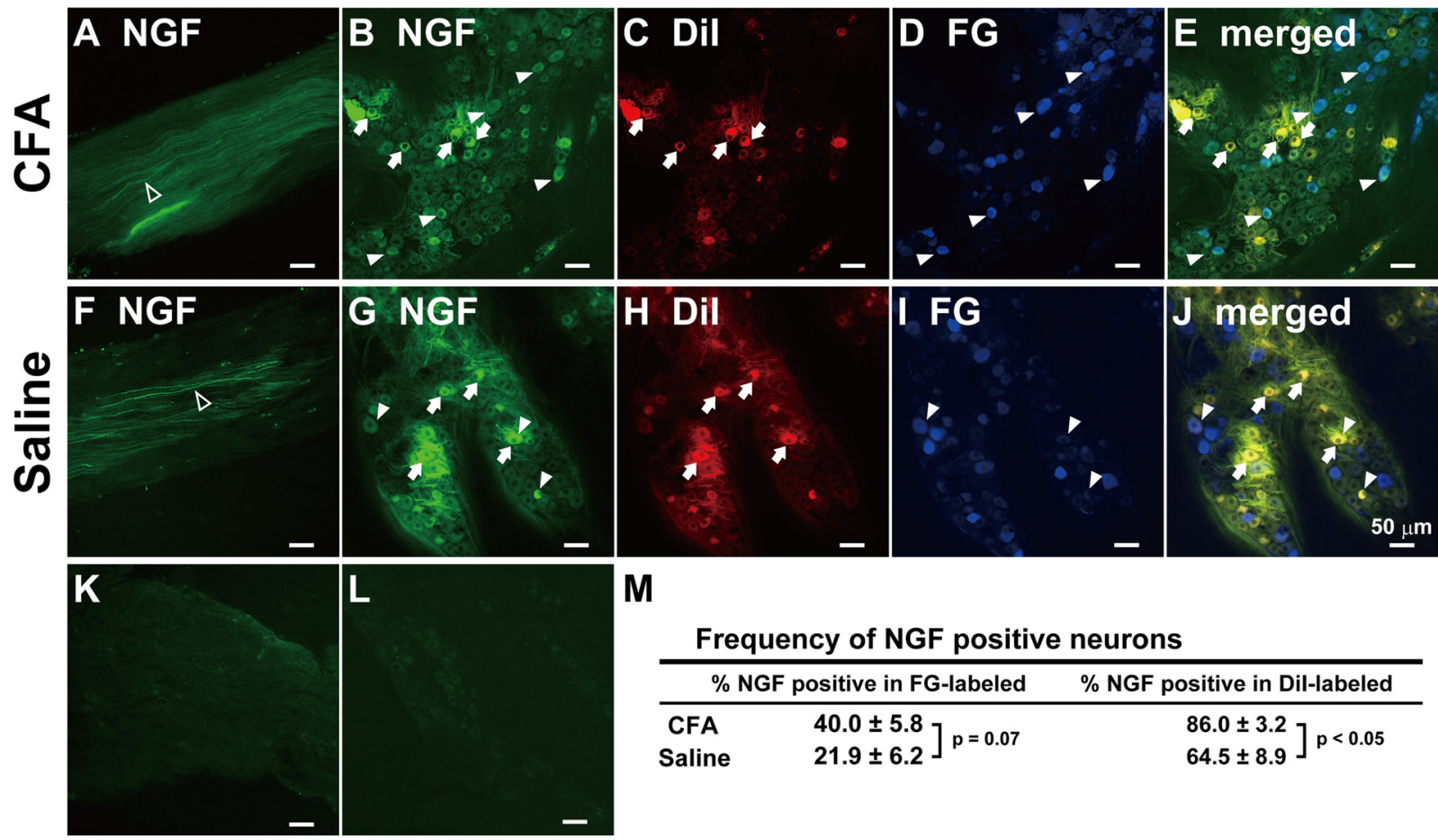

M

Frequency of NGF positive neurons

\begin{tabular}{lrr}
\hline \multicolumn{2}{c}{$\%$ NGF positive in FG-labeled } & \% NGF positive in Dil-labeled \\
\hline CFA & $40.0 \pm 5.8$ \\
Saline & $21.9 \pm 6.2] p=0.07$ & $86.0 \pm 3.2$ \\
\end{tabular}

Figure 10. Mandibular nerve fibers were labeled by $\beta$-NGF which was administrated into the lower lip with CFA $(\boldsymbol{A})$ or saline $(\boldsymbol{F})$. On day 1 after $\beta$-NGF administration into the lower lip with CFA or saline, $\beta$-NGF-positive whisker pad or lower lip TG neurons defined by FG or Dil, respectively. $\boldsymbol{B}, \boldsymbol{G}, \beta$-NGF-positive TG neurons. $\boldsymbol{C}, \boldsymbol{H}$, Dil-labeled TG neurons. $\boldsymbol{D}$, I, FG-labeled TG neurons. $\boldsymbol{E}$, J, Diland FG-labeled $\beta$-NGF-positive TG neurons. Mandibular nerve fibers $(\boldsymbol{K})$ and TG neurons $(\boldsymbol{L})$ on day 1 after labeled BSA administration into the lower lip with CFA. Open arrow, $\beta$-NGF-positive nerve fibers. Arrow, Dil-labeled $\beta$-NGF-positive TG neurons. Arrowhead, FG-labeled $\beta$-NGF-positive TG neurons. Scale bar, $50 \mu \mathrm{m}$. $\boldsymbol{M}$, Frequency of $\beta$-NGF-positive neurons in FG- or Dil-labeled TG neurons after CFA or saline injection into the lower lip ( $n=5$ in CFA-injected group; $n=4$ in saline-injected group; Student's $t$ test).

Release of NGF from TG neurons innervating the inflamed lip tissue

Alexa Fluor 488-labeled $\beta$-NGF that was administrated into the lower lip together with CFA or saline was expressed in the mandibular nerve fibers (Fig. 10A,F), whisker pad and lower lip TG neurons (Fig. $10 B-E, G-J$ ). No Alexa Fluor 488-labeled BSA was expressed in the mandibular nerve fibers and TG neurons (Fig. $10 K, L)$. Mean percentage of DiI-labeled NGF-positive neurons in CFA-injected group was significantly larger than that of salineinjected group (CFA-injected, $86.0 \pm 3.2 \%$; saline-injected, $64.5 \pm 8.9 \%$; $p<0.05$ ) (Fig. 10M). Moreover, mean percentage of FG-labeled NGF-positive neurons in CFA-injected group was also slightly larger than that of saline-injected group (CFAinjected, $40.0 \pm 5.8 \%$; saline-injected, $21.9 \pm 6.2 \% ; p=0.07)$.

\section{Effect of tyrosine kinase receptor inhibitor K252a}

administrated into TG on heat hyperalgesia

Four days after CFA injection into the lower lip, head withdrawal latency to heat stimulation of the whisker pad skin was not altered in mice that had received daily $\mathrm{K} 252 \mathrm{a}$ administration (day 0 through day 3) into the TG ipsilateral to CFA injection (Fig. $11 A)$. However, the head withdrawal latency was significantly shortened after daily vehicle injection into the lower lip compared with that before injection $(p<0.05)$ (Fig. $11 B$ ). Moreover, daily K252a alone had no effect on the head withdrawal latency (data not shown).

NGF concentration and its mRNA expression after CFA injection into the lower lip

Concentrations of NGF were measured by ELISA after CFA injection into the lower lip. In both V1-V2 and V3 of the TG, NGF concentration (in picograms per milliliter) was significantly in-
A

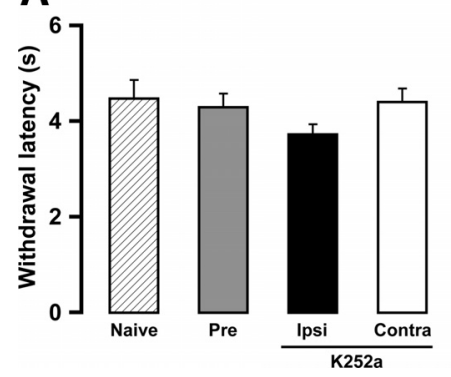

B

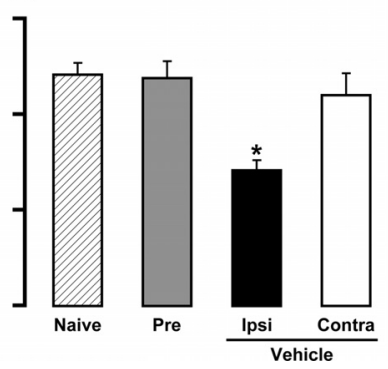

Figure 11. Effects of intraganglionic administration of K252a (A) or vehicle $(\boldsymbol{B})$ into TG on heat sensitivity of whisker pad skin on day 4. Diagonal, whisker pad skin of naive. Gray, whisker pad skin of preinjection. Black, Ipsilateral whisker pad skin. White, Contralateral whisker pad skin. ${ }^{*} p<0.05$ ( $n=6$ in each group; one-way ANOVA followed by Bartlett's multiplecomparison test). Error bars indicate SEM.

creased on days 1 and 10 after CFA injection into the lower lip $(p<0.05)$ (Fig. 12A). In V3, NGF concentration after CFA injection into the lower lip was significantly increased on day 1 . NGF concentration gradually declined, and there was no significant difference in NGF concentration between CFA-injected and saline-injected TG on day 10. In V1-V2, NGF concentration after CFA injection into the lower lip was significantly increased on day 1 , and this increase was sustained throughout the experimental period $(p<0.05)$. No significant changes in NGF concentration of TG to saline-injected group in both V1-V2 and V3 were observed during the experimental period. On day 1 after CFA injection into the lower lip, there were no significant differences in NGF concentration in both V1-V2 and V3 between animals with removal of the ipsilateral SCG and sham-operated (data not shown). 
In the lower lip, NGF concentration was significantly increased on days 1 and 4 after CFA injection into the lower lip (Fig. $12 \mathrm{~B})$. The NGF concentration gradually decreased, and there was no significant difference between CFA-injected and naive lower lip on day 10. In whisker pad skin and supraorbital tissue, there were no significant differences in NGF concentration during the experimental period.

The expression of NGF mRNA was also measured by reverse transcriptionPCR at $12 \mathrm{~h}$ after CFA injection into the lower lip (Fig. 12C). NGF mRNA was expressed in the lower lip despite no expression in both V1-V2 and V3 of the TG. NGF mRNA never expressed in the lower lip and TG after saline injection into the lower lip.

\section{Discussion}

\section{Model of ectopic trigeminal} inflammatory pain

Among the abundance of animal models of inflammatory pain, some models have been developed for the trigeminal region. Local injection of CFA (Shinoda et al., 2005; Tashiro et al., 2009), capsaicin (Honda et al., 2008), carrageenan (Teixeira et al., 2010), or formalin (Wu et al., 2009) induces local inflammation in the trigeminal region and results in pain-related behavior, including mechanical and heat hypersensitivity at the inflamed site. However, these models assessed changes in mechanical or heat sensitivity at the inflamed site; few models inducing ectopic inflammatory pain in the noninflamed adjacent division of the trigeminal nerve have been developed in the orofacial region.

In the present study, mice with local inflammation induced by CFA injection into the lower lip demonstrated significant heat hyperalgesia that could be measured by heat stimulation of whisker pad skin. No significant changes in heat sensitivity of the contralateral whisker pad skin were observed. These results indicate that heat hyperalgesia in V2 can be induced by local inflammation in V3. Development of useful animal models for this condition will most likely increase our knowledge of the mechanisms underlying ectopic orofacial inflammatory pain.

\section{NGF expression in TG neurons}

NGF in peripheral inflamed tissue is elevated in several painful inflammatory conditions in humans, including arthritis (Aloe et al., 1992; Halliday et al., 1998), cystitis (Lowe et al., 1997; Oddiah et al., 1998), and prostatitis (Miller et al., 2002). In the inflammatory state, numerous inflammatory cytokines such as interleukin-1, tumor necrosis factor- $\alpha$, and interleukin-6 induce NGF production in fibroblasts, endothelial cells, and glial cells in peripheral tissues (Otten et al., 2000; Abe et al., 2007). In animal studies, the concentration of NGF in inflamed tissue increases in response to inflammation produced by injection of some irritants such as capsaicin, endotoxin, turpentine, or trinitrobenzene sulfonic acid (Oddiah et al., 1998; Stanzel et al., 2008; Chidiac et al., 2009).
C

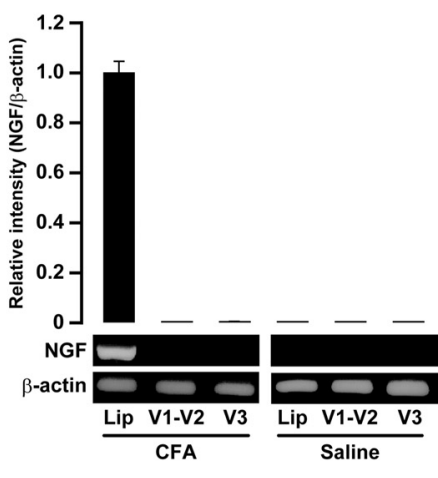

Figure 12. Total NGF protein concentration (in picograms per milliliter) in $\mathrm{TG}$ of $\mathrm{V} 1-\mathrm{V} 2$ and $\mathrm{V} 3$ pre and on days $0.5,1,4$, and 10 (in picograms per milliliter) in lower lip, whiske saline-injected ( $n=5$ in each group; two-way ANOVA followed by Bonferroni's multiple-comparisons test). Error bars indicate Heat hyperalgesia !!!

Figure 13. Schematic presentation of NGF contribution to ectopic heat hyperalgesia of whisker pad skin caused by lower lip inflammation. Upregulation and/or sensitization of TRPV1 in TG neurons in V1-V2 induced by NGF transported from the inflamed lower lip may facilitate the transmission of nociceptive information.

In inflamed peripheral tissue, NGF receptors, TrkA and p75 localized in the distal axons are activated on binding of NGF, the ligand-receptor complex is formed, internalized, and retrogradely transported to the soma of sensory neurons (Niewiadomska et al., 2010). Neurons that contain NGF secrete NGF into the extracellular space after neural excitation, resulting in an increase in NGF concentration in the extracellular fluid in vitro (Blöchl and Thoenen, 1995; Hotta et al., 2009).

In the present study, NGF concentrations in TG, whisker pad skin, and supraorbital tissue were measured after CFA injection into the lower lip. In whisker pad skin and supraorbital tissue, there were no changes in NGF concentrations after CFA injection into the lower lip. However, NGF concentrations in the lower lip, V1-V2, and V3 of TG significantly increased, and removal of the ipsilateral SCG did not affect the increase of NGF concentration in both V1-V2 and V3 of TG. After injection of CFA mixed with labeled NGF into the lower lip, labeled NGF was detected in the mandibular nerve fibers and the number of NGF-positive whisker pad and lower lip TG neurons increased. NGF mRNA was expressed in the lower lip after CFA injection into the lower lip, but not in both V1-V2 and V3 of TG.

These findings suggest that NGF produced in the lower lip locally after local inflammation binds to NGF receptors in the 
terminal membrane of nociceptors and is transported to the soma of TG neurons and secreted to the extracellular space, resulting in an increase in NGF concentration in both V1-V2 and V3 of TG.

\section{TRPV1 expression in TG neurons}

We demonstrated that the number of TRPV1-positive TG neurons significantly increased in both V1-V2 and V3 after CFA injection into the lower lip, and protein expression of TRPV1 was also significantly greater than that of saline-injected TG despite no change in the number of total TG neurons. In addition, daily neutralizing anti-NGF antibody application to the inflamed lower lip suppressed the increment of TRPV1-positive TG neurons in both V1-V2 and V3.

In sensory neurons, the three MAPK families of ERK, p38, and c-Jun N-terminal kinase are expressed by NGF signaling (Ji et al., 2002; Zhuang et al., 2004; Doya et al., 2005). Activation of downstream transcription factors by these MAPKs contributes to the transcriptional changes in sensory neurons that are associated with heat hyperalgesia (Ji et al., 2002). Indeed, retrograde NGF signaling from peripheral terminals in the inflamed tissue to the soma of nociceptive neurons enhances the expression of several proteins, such as TRPV1 (Delcroix et al., 2003), substance P (Yang et al., 2007; Ruiz and Baños, 2009), and brain-derived neurotrophic factor (BDNF) (Michael et al., 1997). NGF signaling also increases the anterograde transport of TRPV1 from the cell body to the peripheral terminals of nociceptors (Ji et al., 2002). In cultured TG neurons, chronic application of NGF led to an increase in TRPV1 expression (Simonetti et al., 2006). NGF in the DRG neurons activates p38, which in turn increases TRPV1 translation (Ji et al., 2002). In humans, TRPV1 mRNA level and its protein expression in esophageal mucosa in esophagitis patients were significantly greater, and NGF gene levels in esophageal mucosa also significantly increased compared with healthy controls (Shieh et al., 2010). A significant increase in TRPV1-immunoreactive fibers was found in biopsies from patients with quiescent inflammatory bowel disease (Akbar et al., 2010). In an animal model, TRPV1 expression in sensory neurons increased in osteoarthritis (Fernihough et al., 2005) and CFA induced inflammation (Ji et al., 2002). In TG neurons in V1-V2, NGF receptors (TrkA and p75) were expressed, and pERK expression was also increased. In addition, spontaneous activity and evoked responses induced by heat stimulation of the whisker pad skin were significantly enhanced after CFA injection into the lower lip.

Together, these findings suggest that NGF secreted into the extracellular space in TG binds to TrkA and/or p75 receptors in TG neurons in V1-V2, resulting in the enhancement of neural excitability, which attributed to an increase in TRPV1 expression in TG neurons in V1-V2.

\section{Involvement of TRPV1 in heat hyperalgesia}

The number of TRPV1-positive TG neurons and TRPV1 proteins were significantly increased in V1-V2 and V3 after CFA injection into the lower lip. To clarify the role of TRPV1 in heat hyperalgesia in the whisker pad skin induced by CFA injection into the lower lip, we also studied the effect of the TRPV1 antagonist SB366791 on the heat hyperalgesia. SB366791 inhibited competitively capsaicin-induced activation of TRPV1 in vitro (Gunthorpe et al., 2004). SB366791 administration also inhibited the development of CFA-induced thermal hyperalgesia in vivo (Kanai et al., 2007). In the present study, SB366791 administration produced reversal of heat hyperalgesia in whisker pad skin after CFA injec- tion into the lower lip. In addition, heat hyperalgesia in the whisker pad skin was depressed by daily application of neutralizing anti-NGF antibody to the inflamed lower lip or a nonspecific tyrosine kinase inhibitor K252a into TG ipsilateral to the inflamed lower lip. BDNF, which is TrkB ligand, is released from TG neurons by neuronal hyperexcitability (Buldyrev et al., 2006), and also tooth pulp inflammation significantly increased BDNF- and TRPV1-positive TG neurons (Tarsa et al., 2010). Because K252a inhibits tyrosine kinase, TrkB and TrkC inhibition by K252a may also be involved in depression of the heat hyperalgesia in whisker pad skin. Moreover, heat hyperalgesia was induced after continuous NGF 2.5S application into the lower lip.

Our results revealed that heat hyperalgesia in whisker pad skin induced by CFA injection into the lower lip depended on TRPV1positive TG neurons in V1-V2 increased by signaling of NGF, which is transported from inflamed peripheral tissue. In addition, head withdrawal latency in the saline-injected group was not altered after SB366791 administration, indicating that the antihyperalgesic effects of SB366791 on whisker pad skin were restricted to heat hyperalgesia associated with CFA injection into the lower lip.

In addition, NGF rapidly induced more robust (20-fold) enhancement of TRPV1 current in acutely dissociated DRG neurons, which respond to capsaicin by activating the phosphatidylinositol 3-kinase and ERK pathways (Zhuang et al., 2004). In addition to upregulation of TRPV1 expression by increased NGF signaling in TG, heat hyperalgesia of whisker pad skin induced by CFA injection into the lower lip might be also involved in sensitizing TRPV1-positive TG neurons by increased NGF signaling.

In conclusion, we have developed a new mouse model of ectopic orofacial pain induced by injection of CFA into the lower lip that resulted in heat hyperalgesia of whisker pad skin, which was diminished by antagonism of TRPV1. We have shown that the increase in the number of TRPV1-positive TG neurons in V1-V2 was induced by lower lip inflammation, and this effect was reduced by daily neutralizing anti-NGF antibody administration into the lower lip. In addition, the concentration of NGF that is transported from the lower lip, in both the V1-V2 and V3 significantly increased after CFA injection into the lower lip. Upregulation and/or sensitization of TRPV1 in TG neurons in V1-V2 after lower lip inflammation may facilitate the transmission of nociceptive information via functional interactions among TG neurons, thus contributing to the resultant enhancement of pain response (Fig. 13).

\section{References}

Abe Y, Akeda K, An HS, Aoki Y, Pichika R, Muehleman C, Kimura T, Masuda K (2007) Proinflammatory cytokines stimulate the expression of nerve growth factor by human intervertebral disc cells. Spine (Phila Pa 1976) 32:635-642.

Akbar A, Yiangou Y, Facer P, Brydon WG, Walters JR, Anand P, Ghosh S (2010) Expression of the TRPV1 receptor differs in quiescent inflammatory bowel disease with or without abdominal pain. Gut 59:767-774.

Aloe L, Tuveri MA, Carcassi U, Levi-Montalcini R (1992) Nerve growth factor in the synovial fluid of patients with chronic arthritis. Arthritis Rheum 35:351-355.

Asano M, Ogura Y, Takenouchi-Ohkubo N, Chihaya H, Chung-Hsing W, Ishikawa K, Kobayashi K, Vaerman JP, Moro I (2004) Endoplasmic reticulum resident, immunoglobulin joining chain, can be secreted by perturbation of the calcium concentration in the endoplasmic reticulum. DNA Cell Biol 23:403-411.

Blöchl A, Thoenen H (1995) Characterization of nerve growth factor (NGF) release from hippocampal neurons: evidence for a constitutive and an unconventional sodium-dependent regulated pathway. Eur J Neurosci $7: 1220-1228$. 
Bonnington JK, McNaughton PA (2003) Signalling pathways involved in the sensitisation of mouse nociceptive neurones by nerve growth factor. J Physiol 551:433-446.

Breese NM, George AC, Pauers LE, Stucky CL (2005) Peripheral inflammation selectively increases TRPV1 function in IB4-positive sensory neurons from adult mouse. Pain 115:37-49.

Buldyrev I, Tanner NM, Hsieh HY, Dodd EG, Nguyen LT, Balkowiec A (2006) Calcitonin gene-related peptide enhances release of native brainderived neurotrophic factor from trigeminal ganglion neurons. J Neurochem 99:1338-1350.

Caterina MJ, Schumacher MA, Tominaga M, Rosen TA, Levine JD, Julius D (1997) The capsaicin receptor: a heat-activated ion channel in the pain pathway. Nature 389:816-824.

Chidiac JJ, Al-Asmar B, Rifai K, Jabbur SJ, Saadé NE (2009) Inflammatory mediators released following application of irritants on the rat injured incisors. The effect of treatment with anti-inflammatory drugs. Cytokine 46:194-200.

Delafoy L, Raymond F, Doherty AM, Eschalier A, Diop L (2003) Role of nerve growth factor in the trinitrobenzene sulfonic acid-induced colonic hypersensitivity. Pain 105:489-497.

Delcroix JD, Valletta JS, Wu C, Hunt SJ, Kowal AS, Mobley WC (2003) NGF signaling in sensory neurons: evidence that early endosomes carry NGF retrograde signals. Neuron 39:69-84.

De Schepper HU, De Winter BY, Van Nassauw L, Timmermans JP, Herman AG, Pelckmans PA, De Man JG (2008) TRPV1 receptors on unmyelinated C-fibres mediate colitis-induced sensitization of pelvic afferent nerve fibres in rats. J Physiol 586:5247-5258.

Doya H, Ohtori S, Fujitani M, Saito T, Hata K, Ino H, Takahashi K, Moriya H, Yamashita T (2005) c-Jun N-terminal kinase activation in dorsal root ganglion contributes to pain hypersensitivity. Biochem Biophys Res Commun 335:132-138.

Dyck PJ, Peroutka S, Rask C, Burton E, Baker MK, Lehman KA, Gillen DA, Hokanson JL, O'Brien PC (1997) Intradermal recombinant human nerve growth factor induces pressure allodynia and lowered heat-pain threshold in humans. Neurology 48:501-505.

Fernández-de-las-Peñas C, Galán-del-Río F, Ortega-Santiago R, JiménezGarcía R, Arendt-Nielsen L, Svensson P (2010) Bilateral thermal hyperalgesia in trigeminal and extra-trigeminal regions in patients with myofascial temporomandibular disorders. Exp Brain Res 202:171-179.

Fernihough J, Gentry C, Bevan S, Winter J (2005) Regulation of calcitonin gene-related peptide and TRPV1 in a rat model of osteoarthritis. Neurosci Lett 388:75-80.

Gold MS, Weinreich D, Kim CS, Wang R, Treanor J, Porreca F, Lai J (2003) Redistribution of $\mathrm{Na}_{\mathrm{V}} 1.8$ in uninjured axons enables neuropathic pain. J Neurosci 23:158-166.

Gunthorpe MJ, Rami HK, Jerman JC, Smart D, Gill CH, Soffin EM, Luis Hannan S, Lappin SC, Egerton J, Smith GD, Worby A, Howett L, Owen D, Nasir S, Davies CH, Thompson M, Wyman PA, Randall AD, Davis JB (2004) Identification and characterisation of SB-366791, a potent and selective vanilloid receptor (VR1/TRPV1) antagonist. Neuropharmacology 46:133-149.

Halliday DA, Zettler C, Rush RA, Scicchitano R, McNeil JD (1998) Elevated nerve growth factor levels in the synovial fluid of patients with inflammatory joint disease. Neurochem Res 23:919-922.

Hefti FF, Rosenthal A, Walicke PA, Wyatt S, Vergara G, Shelton DL, Davies AM (2006) Novel class of pain drugs based on antagonism of NGF. Trends Pharmacol Sci 27:85-91.

Honda K, Kitagawa J, Sessle BJ, Kondo M, Tsuboi Y, Yonehara Y, Iwata K (2008) Mechanisms involved in an increment of multimodal excitability of medullary and upper cervical dorsal horn neurons following cutaneous capsaicin treatment. Mol Pain 4:59.

Hotta H, Kagitani F, Kondo M, Uchida S (2009) Basal forebrain stimulation induces NGF secretion in ipsilateral parietal cortex via nicotinic receptor activation in adult, but not aged rats. Neurosci Res 63:122-128.

Ji RR, Samad TA, Jin SX, Schmoll R, Woolf CJ (2002) p38 MAPK activation by NGF in primary sensory neurons after inflammation increases TRPV1 levels and maintains heat hyperalgesia. Neuron 36:57-68.

Kamp EH, Jones RC 3rd, Tillman SR, Gebhart GF (2003) Quantitative assessment and characterization of visceral nociception and hyperalgesia in mice. Am J Physiol Gastrointest Liver Physiol 284:G434-G444.

Kanai Y, Hara T, Imai A, Sakakibara A (2007) Differential involvement of TRPV1 receptors at the central and peripheral nerves in CFAinduced mechanical and thermal hyperalgesia. J Pharm Pharmacol 59:733-738.

Kitamura N, Konno A, Kuwahara T, Komagiri Y (2005) Nerve growth factor-induced hyperexcitability of rat sensory neuron in culture. Biomed Res 26:123-130.

Lewin GR, Rueff A, Mendell LM (1994) Peripheral and central mechanisms of NGF-induced hyperalgesia. Eur J Neurosci 6:1903-1912.

Lowe EM, Anand P, Terenghi G, Williams-Chestnut RE, Sinicropi DV, Osborne JL (1997) Increased nerve growth factor levels in the urinary bladder of women with idiopathic sensory urgency and interstitial cystitis. Br J Urol 79:572-577.

Maixner W, Fillingim R, Sigurdsson A, Kincaid S, Silva S (1998) Sensitivity of patients with painful temporomandibular disorders to experimentally evoked pain: evidence for altered temporal summation of pain. Pain 76:71-81.

Michael GJ, Averill S, Nitkunan A, Rattray M, Bennett DL, Yan Q, Priestley JV (1997) Nerve growth factor treatment increases brain-derived neurotrophic factor selectively in TrkA-expressing dorsal root ganglion cells and in their central terminations within the spinal cord. J Neurosci 17:8476-8490.

Miller LJ, Fischer KA, Goralnick SJ, Litt M, Burleson JA, Albertsen P, Kreutzer DL (2002) Nerve growth factor and chronic prostatitis/chronic pelvic pain syndrome. Urology 59:603-608.

Niewiadomska G, Mietelska-Porowska A, Mazurkiewicz M (2010) The cholinergic system, nerve growth factor and the cytoskeleton. Behav Brain Res. Advance online publication. Retrieved April 19, 2011. doi:10.1016/j.bbr.2010.02.024.

Oddiah D, Anand P, McMahon SB, Rattray M (1998) Rapid increase of NGF, BDNF and NT-3 mRNAs in inflamed bladder. Neuroreport 9: $1455-1458$.

Omagari D, lijima M, Suguro H, Sato I, Asano M, Moro I (2008) Differential distribution of mouse polymeric immunoglobulin receptor (mplgR): establishment of enzyme-linked immunosorbent assay system for mplgR. Scand J Immunol 68:543-551.

Otten U, März P, Heese K, Hock C, Kunz D, Rose-John S (2000) Cytokines and neurotrophins interact in normal and diseased states. Ann N Y Acad Sci 917:322-330.

Ruiz G, Baños JE (2009) Heat hyperalgesia induced by endoneurial nerve growth factor and the expression of substance $\mathrm{P}$ in primary sensory neurons. Int J Neurosci 119:185-203.

Rukwied R, Mayer A, Kluschina O, Obreja O, Schley M, Schmelz M (2010) NGF induces non-inflammatory localized and lasting mechanical and thermal hypersensitivity in human skin. Pain 148:407-413.

Shieh KR, Yi CH, Liu TT, Tseng HL, Ho HC, Hsieh HT, Chen CL (2010) Evidence for neurotrophic factors associating with TRPV1 gene expression in the inflamed human esophagus. Neurogastroenterol Motil 22: 971-977, e252.

Shim B, Ringkamp M, Lambrinos GL, Hartke TV, Griffin JW, Meyer RA (2007) Activity-dependent slowing of conduction velocity in uninjured L4 C fibers increases after an L5 spinal nerve injury in the rat. Pain 128:40-51.

Shinoda M, Ozaki N, Asai H, Nagamine K, Sugiura Y (2005) Changes in $\mathrm{P} 2 \mathrm{X} 3$ receptor expression in the trigeminal ganglion following monoarthritis of the temporomandibular joint in rats. Pain 116:42-51.

Shu X, Mendell LM (1999) Nerve growth factor acutely sensitizes the response of adult rat sensory neurons to capsaicin. Neurosci Lett 274:159-162.

Simonetti M, Fabbro A, D’Arco M, Zweyer M, Nistri A, Giniatullin R, Fabbretti E (2006) Comparison of P2X and TRPV1 receptors in ganglia or primary culture of trigeminal neurons and their modulation by NGF or serotonin. Mol Pain 2:11.

Stanzel RD, Lourenssen S, Blennerhassett MG (2008) Inflammation causes expression of NGF in epithelial cells of the rat colon. Exp Neurol 211:203-213.

Tarsa L, Balkowiec-Iskra E, Kratochvil FJ 3rd, Jenkins VK, McLean A, Brown AL, Smith JA, Baumgartner JC, Balkowiec A (2010) Tooth pulp inflammation increases brain-derived neurotrophic factor expression in rodent trigeminal ganglion neurons. Neuroscience 167:1205-1215.

Tashiro A, Okamoto K, Bereiter DA (2009) Chronic inflammation and estradiol interact through MAPK activation to affect TMJ nociceptive 
processing by trigeminal caudalis neurons. Neuroscience 164:18131820.

Teixeira JM, Oliveira MC, Nociti FH Jr, Clemente-Napimoga JT, Pelegrinida-Silva A, Parada CA, Tambeli CH (2010) Involvement of temporomandibular joint $\mathrm{P} 2 \mathrm{X} 3$ and $\mathrm{P} 2 \mathrm{X} 2 / 3$ receptors in carrageenan-induced inflammatory hyperalgesia in rats. Eur J Pharmacol 645:79-85.

Tominaga M, Caterina MJ (2004) Thermosensation and pain. J Neurobiol 61:3-12.

Tominaga M, Tominaga T (2005) Structure and function of TRPV1. Pflugers Arch 451:143-150.

Varga A, Németh J, Szabó A, McDougall JJ, Zhang C, Elekes K, Pintér E, Szolcsányi J, Helyes Z (2005) Effects of the novel TRPV1 receptor antagonist SB366791 in vitro and in vivo in the rat. Neurosci Lett 385:137-142.
Wu LA, Huang J, Wang W, Wang W, Wang XJ, Wu SX (2009) Downregulation of $\mathrm{K}^{+}-\mathrm{Cl}^{-}$co-transporter 2 in mouse medullary dorsal horn contributes to the formalin-induced inflammatory orofacial pain. Neurosci Lett 457:36-40.

Yang XD, Liu Z, Liu HX, Wang LH, Ma CH, Li ZZ (2007) Regulatory effect of nerve growth factor on release of substance $\mathrm{P}$ in cultured dorsal root ganglion neurons of rat. Neurosci Bull 23:215-220.

Zhuang ZY, Xu H, Clapham DE, Ji RR (2004) Phosphatidylinositol 3-kinase activates ERK in primary sensory neurons and mediates inflammatory heat hyperalgesia through TRPV1 sensitization. J Neurosci 24:8300-8309.

Zimmermann M (1983) Ethical guidelines for investigations of experimental pain in conscious animals. Pain 16:109-110. 